\title{
O PROGRAMA DE GERENCIAMENTO DOS RESÍDUOS LABORATORIAIS DO DEPTO DE QUÍMICA DA UFPR
}

Carlos Jorge da Cunha*

Departamento de Química, Universidade Federal do Paraná, Centro Politécnico, CP 19081, 81531-990, Curitiba - PR.

Recebido em 26/6/00; aceito em 16/10/00

\begin{abstract}
THE LABORATORY WASTE MANAGEMENT PROGRAM OF THE CHEMISTRY DEPARTMENT OF UFPR. The Laboratory Waste Management Program of the Chemistry Department of UFPR started on 1997 and was developed to meet the requirements of co-processing in cement kiln and those of the respective regulation. The in-lab procedures for waste collection and treatment were devised taking into account their cost, simplicity and wide range of application to the various types of residues generated. The program works with a five step annual journey : 1) Waste collection and treatment, 2) Bulk Storage, 3) Licensing (for transportation and co-processing), 4) Transportation and 5) Co-processing.
\end{abstract}

Keywords: residues; co-processing; treatment; management; laboratory.

\section{INTRODUÇÃO}

Resíduos químicos gerados nos laboratórios do DQUI vinham sendo coletados e acumulados, há vários anos, por muitos de seus integrantes preocupados com o meio ambiente. Também acumularam-se vários frascos abandonados com resíduos e frascos de reagentes que perderam o rótulo pela ação do tempo. Apesar das precárias condições de armazenamento, nunca ocorreram explosões, intoxicações agudas ou incêndios ocasionados por estes resíduos.

O programa de gerenciamento de resíduos surgiu da mobilização de um grupo de Professores conscientizados para o problema e não como fruto de imposição de lei ou de pressões causadas por ações paliativas pós-tragédias, muito comuns no país.

Basicamente havia três alternativas para o destino final dos resíduos químicos do DQUI : o aterramento controlado (na Cidade Industrial de Curitiba), a incineração (em São Paulo ou Rio de Janeiro) e o co-processamento em forno de cimento (na Região Metropolitana de Curitiba). O co-processamento ${ }^{1}$ foi escolhido pois é o mais versátil e efetivo método de tratamento para o tipo de resíduo gerado em nossos laboratórios e tem sido feito como cortesia pela Companhia Cimenteira Rio Branco do grupo Votoran localizada em Rio Branco do Sul na Região Metropolitana de Curitiba.

O programa foi baseado no co-processamento em forno de cimento $^{\#}$. O co-processamento consiste em adicionar-se resíduos químicos, combustíveis ou não, na forma de sólidos líquidos ou pastas, ao forno de cimento durante a formação do clínquer. Os líquidos combustíveis são misturados e queimados com o combustível auxiliar do forno, os sólidos e pastosos são adicionados em bocas de lobo que levam ao interior da parte alta do forno e os aquosos são adicionados junto com a água de resfriamento dos gases do forno. No Paraná o coprocessamento é licenciado para tratar: ácidos e bases, solventes halogenados e não halogenados, cianetos e arsenatos, sais de quase todos os metais exceto os de mercúrio, cádmio e tálio. Também é vetado o tratamento de agrotóxicos, materiais radioativos, explosivos, material infeccioso e bifenilas policloradas (PCB's).

\footnotetext{
* e-mail: cjcunha@quimica.ufpr.br

\# O co-processamento em forno de cimento não está disponível em todos os estados do Brasil. Antes de montar um programa de tratamento de resíduos a instituição deve consultar o orgão ambiental estadual para solicitar alternativas.
}

O programa foi então montado em jornadas anuais com cinco etapas: 1) Coleta e tratamento, 2) Armazenamento, 3) Licenciamento (para transporte e co-processamento), 4) Transporte e 5) Co-processamento.

\section{ETAPA 1}

A primeira etapa é realizada dentro de cada um dos 28 laboratórios e consiste em quatro fases: coleta, neutralização, teste de incompatibilidade e mistura em bombona. Os coordenadores do programa fornecem treinamento.

Fase 1-1) Coleta. A coleta dos resíduos é feita em frascos pequenos, tipicamente de $1 \mathrm{~L}$, e o conteúdo do frasco é registrado em uma ficha de resíduos (Figura 1) que acompanha cada frasco. Estes frascos podem ser usados para coletar resíduos de um pesquisador, de um aluno, de várias pessoas da mesma bancada ou de várias pessoas que trabalham com uma mesma linha de pesquisa. A definição de quantos frascos de coleta ficam disponíveis e as suas localizações fica a critério dos usuários de cada laboratório. A mistura de vários resíduos em um mesmo frasco requer o conhecimento da possível incompatibilidade entre eles (Tabela 1). O conteúdo dos frascos não deve ultrapassar a marca de $80 \%$ de sua capacidade.

Fase 1-2) Neutralização. Quando um ou mais frascos ficam cheios eles devem ser neutralizados. Esta neutralização consiste em minimizar a periculosidade do resíduo por meio de reações químicas que aumentem a sua compatibilidade com demais resíduos. Na Tabela 1 podem ser vistas os vários tipos de substâncias incompatíveis. As substâncias listadas na Tabela 1 podem ser divididas em seis grandes classes de incompatibilidade: $\{1\}$ ácido, $\{2\}$ base, $\{3\}$ oxidante, $\{4\}$ redutor, $\{5\}$ metal ou liga, e $\{6\}$ hidrolisável. Para neutralizar* sua incompatibilidade recomenda-se reagir os ácidos fortes com bases fracas, reagir as bases fortes com ácidos fracos, reagir os oxidantes enérgicos com um redutor brando, reagir os redutores enérgicos com oxidante brando e reagir os hidrolisáveis com água. Os metais e ligas devem ser lavados, secos e guardados como resíduos sólidos. A equipe que coordena o programa fornece orientação para se tratar substâncias que não se enquadram nestas classes ou que mereçam atenção especial ${ }^{2}$.

\footnotetext{
"Grande cuidado deve ser tomado ao se realizar as operações de neutralização pois muitas reações são extremamente perigosas
} 
Tabela 1. Produtos Químicos Incompatíveis. Os códigos entre chaves indicam a classificação em $\{1\}$ ácido, $\{2\}$ base,

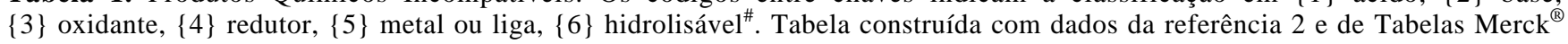
para laboratório.

\begin{tabular}{|c|c|}
\hline Substância & Incompatível com \\
\hline acetileno & cloro $\{3\}$, bromo $\{3\}$, flúor $\{3\}$, cobre $\{5\}$, prata $\{5\}$, mercúrio $\{5\}$ \\
\hline acetona & ácido nítrico $\{1\}$, ácido sulfúrico $\{1\}$ \\
\hline ácido acético $\{1\}$ & $\begin{array}{l}\text { óxido de cromo(VI) }\{1\} \text {, ácido nítrico }\{1\} \text {, álcoois, etilenoglicol, ácido perclórico }\{1\} \text {, } \\
\text { peróxidos }\{3\} \text {, permanganatos }\{3\} \text {. }\end{array}$ \\
\hline ácido cianídrico $\{1\}$ & ácido nítrico $\{1\}$, álcalis $\{2\}$ \\
\hline ácido fluorídrico $\{1\}$ & amoníaco $\{2\}$ e gás amônia $\{2\}$ \\
\hline ácido nítrico concentrado $\{1\}$ & $\begin{array}{l}\text { ácido acético }\{1\} \text {, anilina }\{2\} \text {, óxido de cromo(VI) }\{3\}\{1\} \text {, ácido cianídrico, sulfeto de } \\
\text { hidrogênio, cobre }\{5\} \text {, bronze }\{5\} \text {, acetona, álcool, líquidos e gases inflamáveis. }\end{array}$ \\
\hline ácido oxálico $\{1\}$ & prata $\{5\}$ e mercúrio $\{5\}$ \\
\hline ácido perclórico $\{1\}$ & $\begin{array}{l}\text { anidrido acético }\{6\}\{1\} \text {, ácido acético }\{1\} \text {, bismuto e suas ligas }\{5\} \text {, álcoois, papel, madeira, } \\
\text { graxas e óleos }\end{array}$ \\
\hline ácido sulfúrico $\{1\}$ & cloratos $\{3\}$, percloratos $\{3\}$, permanganatos $\{3\}$ \\
\hline alquil alumínio $\{6\}$ & água \\
\hline $\begin{array}{l}\text { amoníaco e gás amônia }\{2\} \\
\text { anilina }\{2\}\end{array}$ & $\begin{array}{l}\text { mercúrio }\{5\} \text {, cloro }\{3\} \text {, bromo }\{5\} \text {, iodo }\{3\} \text {, hipoclorito de cálcio }\{3\} \text {, ácido fluorídrico }\{1\} \\
\text { ácido nítrico }\{1\}\{3\} \text { e peróxido de hidrogênio }\{3\}\end{array}$ \\
\hline arseniatos & agentes redutores $\{4\}$ (geram arsina) \\
\hline azidas & ácidos (geram azida de hidrogênio) $\{1\}$ \\
\hline bromo $\{3\}$ & $\begin{array}{l}\text { amoníaco }\{2\} \text {, acetileno, butadieno, butano, metano, propano, hidrogênio, benzina, benzeno, } \\
\text { metais em pó }\{5\} \text {, carbeto de sódio }\{6\}\end{array}$ \\
\hline cal (óxido de cálcio) $\{2\}$ & água e ácidos (exotérmica) $\{1\}$ \\
\hline carvão ativado $\{4\}$ & hipoclorito de cálcio $\{3\}$, oxidantes $\{3\}$ \\
\hline cianetos & ácidos $\{1\}$ (geram ácido cianídrico) \\
\hline cloratos $\{3\}$ & $\begin{array}{l}\text { sais de amônio, ácidos }\{1\} \text {, metais em pó }\{5\} \text {, enxôfre, substâncias orgânicas inflamáveis ou } \\
\text { em pó. }\end{array}$ \\
\hline cloro $\{3\}$ & $\begin{array}{l}\text { amônia }\{2\} \text {, acetileno, butadieno, butano, metano, propano, hidrogênio, benzina, benzeno, } \\
\text { metais em pó }\{5\} \text {, carbeto de sódio }\{6\}\end{array}$ \\
\hline cobre $\{5\}$ & acetileno, peróxido de hidrogênio $\{3\}$ \\
\hline dióxido de cloro $\{3\}$ & amônia $\{2\}$, metano, fosfina $\{4\}$, sulfeto de hidrogênio \\
\hline flúor $\{3\}$ & oxida quase tudo, guarde-o em separado. \\
\hline fósforo (branco) $\{4\}$ & álcalis $\{2\}$ (geram fosfina), ar, oxigênio $\{3\}$, enxôfre, compostos com oxigênio \\
\hline hidrazina $\{4\}$ & peróxido de hidrogênio $\{3\}$, ácido nítrico $\{1\}\{3\}$, outros oxidantes $\{3\}$ \\
\hline hidrocarbonetos & flúor $\{3\}$, cloro $\{3\}$, bromo $\{3\}$, óxido de cromo(VI) $\{3\}\{1\}$, peróxido de sódio $\{3\}$ \\
\hline hidroperóxido de cumeno $\{3\}$ & ácidos orgânicos $\{1\}$ e inorgânicos $\{1\}$ \\
\hline hipocloritos $\{3\}$ & ácidos $\{1\}$ \\
\hline iodo $\{3\}$ & $\{2\}$, hidrogênio. \\
\hline líquidos inflamáveis & $\begin{array}{l}\text { nitrato de amônio, óxido de cromo(VI) }\{1\}\{3\} \text {, peróxido de hidrogênio }\{3\} \text {, ácido nítrico } \\
\{1\}\{3\} \text {, peróxido de sódio }\{3\} \text {, halogênios }\{3\}\end{array}$ \\
\hline mercúrio $\{5\}$ & acetileno, amônia $\{2\}$, amoníaco $\{2\}$ \\
\hline metais alcalinos $\{5\}\{6\}$ & água, hidrocarbonetos halogenados, dióxido de carbono, halogênios $\{3\}$ \\
\hline nitrato de ar & $\begin{array}{l}\text { ácidos }\{1\} \text {, metais em pó }\{5\} \text {, líquidos inflamáveis, cloratos }\{3\} \text {, nitritos }\{3\} \text {, enxôfre, } \\
\text { substâncias orgânicas inflamáveis ou em pó. }\end{array}$ \\
\hline nitratos & ácido sulfúrico $\{1\}\{3\}$ (gera dióxido de nitrogênio) \\
\hline nitritos $\{3\}$ & ácidos $\{1\}$ (geram fumos nitrosos), nitrato de amônio, sais de amônio. \\
\hline nitroparafinas & bases inorgânicas $\{2\}$, aminas $\{2\}$ \\
\hline $\begin{array}{l}\text { óxido de cromo (VI) } \\
\text { (ácido crômico) }\{1\}\{3\}\end{array}$ & ácido acético $\{1\}$, naftaleno, cânfora, glicerina, benzina, álcoois, líquidos inflamáveis \\
\hline oxigênio (gás puro) $\{3\}$ & óleos, graxas, hidrogênio, substâncias inflamáveis. \\
\hline perclorato de potássio $\{3\}$ & $\begin{array}{l}\text { sais de amônio, ácidos }\{1\} \text {, metais em pó }\{5\} \text {, enxôfre, substâncias orgânicas inflamáveis } \\
\text { ou em pó. }\end{array}$ \\
\hline permanganato de potássio $\{3\}$ & glicerina, etilenoglicol, benzaldeído, ácido sulfúrico $\{1\}\{3\}$ \\
\hline peróxido de hidrogênio $\{3\}$ & $\begin{array}{l}\text { cobre }\{5\} \text {, cromo }\{5\} \text {, ferro }\{5\} \text {, metais }\{5\} \text {, sais metálicos, álcoois, acetona, substâncias } \\
\text { orgânicas, anilina }\{2\} \text {, nitrometano, substâncias inflamáveis sólidas ou líquidas }\end{array}$ \\
\hline peróxido de sódio $\{3\}$ & $\begin{array}{l}\text { substâncias oxidáveis }\{3\} \text {, metanol, etanol, ácido acético glacial }\{1\} \text {, anidrido acético }\{1\} \\
\{6\} \text {, disulfeto de carbono, glicerina, etilenoglicol, acetato de etila, acetato de metila, furfural, } \\
\text { benzaldeído. }\end{array}$ \\
\hline peróxidos orgânicos $\{3\}$ & ácidos orgânicos $\{1\}$ ou inorgânicos $\{1\}$ \\
\hline prata $\{5\}$ & acetileno, ácido oxálico $\{1\}\{4\}$, ácido tartárico $\{1\}$, sais de amônio \\
\hline selenetos $\{4\}$ & redutores $\{4\}$ (geram seleneto de hidrogênio) \\
\hline sulfeto de hidrogênio & ácido nítrico fumegante $\{1\}\{3\}$, gases oxidantes $\{3\}$ \\
\hline sulfetos $\{4\}$ & ácidos $\{1\}$ (ger \\
\hline teluretos & redutores $\{4\}$ (geram telureto de hidrogênio) $\{4\}$ \\
\hline
\end{tabular}

${ }^{\#}$ Hidrolisável neste contexto refere-se a materiais que reagem com a água. 
Fase 1-3) Teste de incompatibilidade. Os resíduos neutralizados são adicionados a uma bombona que deve conter apenas substâncias compatíveis (Tabela 1). Por motivos de segurança, os coordenadores do programa sugerem que seja feito um teste de incompatibilidade. Este teste consiste em juntar, em um becher, uma amostra de 1 gota do resíduo neutralizado com uma amostra de 1 gota do conteúdo da bombona. Caso não haja reação violentamente exotérmica e nem liberação de gás o teste deve ser repetido com $1 \mathrm{~mL}$ de cada resíduo. Caso não haja reação violentamente exotérmica e nem liberação de gás os resíduos serão considerados compatíveis. $O$ teste deve ser feito na capela.

Fase 1-4) Mistura em bombona. Uma vez considerado compatível com o da bombona o resíduo neutralizado pode ser adicionado à ela. A ficha de resíduo do material recém adicionado deve ser anexada às fichas que acompanham a bombona. O número da bombona deve ser escrito nesta ficha. O conteúdo da bombona não deve ultrapassar a marca de $80 \%$ de sua capacidade que, em geral, é de 25 a $30 \mathrm{~L}$.

\section{FICHA DE IDENTIFICAÇÃO DE RESÍDUO QUÍMICO - UFPR.}

Preencha uma ficha para cada frasco contendo resíduos químicos e prenda-a ao frasco. Resíduos compativeis devem ser misturados, sempre que possivel, em um só frasco. Responsável

Departamento Laboratório

Telefone Setor

Data do preenchimento da ficha _______

Marque $\operatorname{com} \mathrm{X}$ as características do resíduo químico:
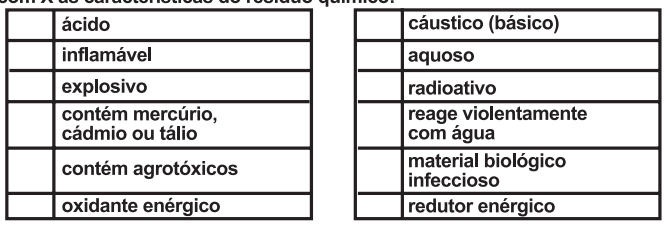

Descrição dos componentes do resíduo (pode agrupar em classes tais como haletos de chumbo, solventes halogenados, hidrocarbonetos, nitrilas, etc):

Marque com ? quando a estimativa de quantidade de um componente não puder ser feita.$$
\text { Marque com ? quando a estimativa de quantidade de um componente năo puder ser felta. }
$$

\begin{tabular}{|l|c|c|}
\hline nome da substância & $\begin{array}{c}\text { quantidade } \\
(\mathrm{mL}, \mathrm{g})\end{array}$ & observaçōes \\
\hline & & \\
\hline & & \\
\hline & & \\
\hline
\end{tabular}

Figura 1. Ficha de Resíduo Químico usada no DQUI - UFPR.

Os resíduos sólidos que necessitam de neutralização são tratados como descrito acima. Os resíduos sólidos, que não necessitam de neutralização, e que estejam secos são embalados em sacos plásticos e acondicionados em baldes de resíduos sólidos. Fichas de resíduo também acompanham cada balde. Os baldes estão disponíveis em cada laboratório.

\section{ETAPAS 2, 3, 4 e 5}

A segunda etapa consiste em armazenar as bombonas e baldes de resíduos em um depósito com acesso restrito, os conteúdos descritos nas fichas são verificados e a acidez do conteúdo das bombonas é conferida. Na terceira etapa os coordenadores do programa recolhem todas as fichas de resíduos e preparam uma lista unificada que é encaminhada à cimenteira para fazer um plano de co-processamento que é encaminhado para o Instituto Ambiental do Paraná (IAP) para licenciamento. Uma vez obtida a licença os resíduos são transportados para a cimenteira e esta é a quarta etapa do programa. O co-processamento dos resíduos é a quinta etapa que marca o fim de uma jornada anual.

O programa necessita de cerca de $\mathrm{R} \$ 1000,00$ por ano para a compra de fichas, lacres, bombonas e baldes (não retornáveis) e reagentes para neutralização. Estes recursos, apesar de pequenos, têm sido cada vez mais difíceis de conseguir tendo em vista os programas de cortes de verbas federais.

\section{NEUTRALIZAÇÕES E INCOMPATIBILIDADES}

Recomenda-se que as neutralizações sejam feitas em baldes plásticos. Com relação à neutralização de ácidos é sugerido o uso de cal hidratada ( $\mathrm{R} \$ 0,50 / \mathrm{Kg}$ ) em conjunto com bicarbonato de sódio $(\mathrm{R} \$ 0,90 / \mathrm{Kg})$. A reação de ácidos com cal hidratada é muito exotérmica ao passo que a reação com bicarbonato de sódio é endotérmica, o uso de ambos reagentes pode ser combinado para evitar superaquecimento do meio reacional. $\mathrm{O}$ bicarbonato de sódio pode também ser usado para neutralizar bases fortes. O pH de uma solução aquosa saturada em bicarbonato de sódio fica próximo de 8 , condição na qual os sistemas sulfeto aquoso e amônia aquosa encontram-se majoritáriamente na forma iônica reduzindo o mau cheiro destas soluções. Para neutralizar redutores pode ser usado peróxido de hidrogênio e para neutralizar oxidantes pode ser usado hidrogenossulfito de sódio. Uma rápida inspeção da Tabela 1 nos permite concluir que caso os ácidos e bases fortes, os oxidantes e redutores enérgicos e os materiais hidrolizáveis sejam neutralizados não sobram incompatibilidades. Os metais e ligas são uma classe de redutores que, em geral, é mais fácil descartar como resíduos sólidos secos do que gastar tempo neutralizando sua ação redutora. Exceções a esta regra são os metais alcalinos e os alcalino-terrosos que podem ser rápidamente neutralizados com água ou ácidos diluídos.

Neste esquema de coleta não há necessidade de se separar os solventes clorados dos não clorados e nem tampouco de se separar os aquosos dos orgânicos. No entanto, caso o conteúdo da bombona esteja separado em duas fases líquidas ambas devem ser submetidas ao teste de incompatibilidade antes da adição de novos resíduos.

Dentro das diretrizes do programa está a orientação aos geradores de resíduos para a possibilidade de substituição do uso de uma substância perigosa por uma não perigosa, minimização da geração de resíduos, recuperação e/ou reciclagem dos resíduos ${ }^{3}$.

A classificação de substâncias e resíduos não identificados pode ser feita com o método estabelecido por Jardim ${ }^{4}$. Na classificação de resíduos um cuidado especial deve ser dado à interpretação do resultado devido a possibilidade de interferências causadas por componentes da mistura.

\section{RESÍDUOS ESPECIAIS}

Como resíduos especiais encontram-se os materiais proibidos para co-processamento tais como agrotóxicos, sais de cádmio, mercúrio e tálio e materiais passíveis de recuperação tais como sais de chumbo, irídio e rutênio. O uso laboratorial dos sais de cádmio, mercúrio e tálio tem sido desencorajado no DQUI mas as quantidades ainda descartadas têm sido coletadas em separado e serão recuperadas como carbonatos ou sulfetos e enviadas para aterramento. O chumbo será recuperado como carbonato sólido seco e encaminhado para fornos de fabricação de chumbo para uso em baterias. Os sais de metais preciosos devem ser tratados e recuperados pelos próprios laboratórios geradores. Os resíduos de agrotóxicos gerados no DQUI estão temporariamente sem destino final pois eram enviados para um depósito da Secretaria Estadual de Agricultura do Paraná que foi desativado recentemente.

\section{VOLUME GERADO}

Todos os resíduos que chegam ao armazenamento devem ter sido inertizados por tratamento químico se necessário. Todas as bombonas contendo líquidos ou pastas devem ser neutras ou levemente básicas e levemente redutoras pois, em caso de mistura acidental, o risco de incompatibilidade é minimizado. 
Os volumes gerados anualmente variam mas são aproximadamente os seguintes :

- sais inorgânicos misturados com água

- solventes e líquidos orgânicos

650 litros/ano

375 litros/ano (pode conter água)

- resíduos sólidos secos 100 litros/ano

- sulfato de cálcio, água e matéria graxa

710 litros/ano (tratamento de solventes)

\section{CONSIDERAÇÕES FINAIS}

O Programa de Gerenciamento de Resíduos do Departamento de Química da UFPR está entrando no seu terceiro ano em fase de consolidação e tem sido referência para outras unidades da Universidade e da região de Curitiba. O Setor de Ciências Biológicas da UFPR já está coletando e tratando seus resíduos químicos que, já no corrente ano, serão processados junto aos do Departamento de Química. O Hospital de Clínicas e o Departamento de Física devem, no próximo ano, ter seus Programas de Gerenciamento de Resíduos Químicos implantados.

\section{RESPONSABILIDADE}

$\mathrm{O}$ autor não se responsabiliza por acidentes que venham a ocorrer por mau uso ou má interpretação das informações contidas neste artigo. As operações de tratamento de resíduos são potencialmente perigosas e devem ser conduzidas somente por profissionais que possuam experiência e conhecimento básico de segurança e trabalho em laboratório químico.

\section{AGRADECIMENTOS}

Agradeço às inúmeras pessoas que contribuíram nas diversas fases do programa em especial a Daniel Melo (Prof coordenador do SSTA-UFPR), Ronaldo Barreto (aluno bolsista trabalho em 1998), Rogério Strapasson (técnico de laboratório), Dário Deschamps Justen (Cia Cimenteira Rio Branco Votoran) e Prof. Marco T. Grassi (DQUI-UFPR).

\section{REFERÊNCIAS}

1. Chadbourne, J. F. In Standard Handbook of Hazardous Waste Treatment and Disposal ; Freeman, H.M.; Ed. ; Mc Graw Hill, New York, 1989; p 8.57.

2. Armour, M. A.; Hazardous Laboratory Chemicals Disposal Guide, CRC press, Boca Raton, 1991.

3. Reinhardt, P. A.; Leonard, K. L.; Ashbrook, P. C.; Pollution Prevention and Waste Minimization in Laboratories, CRC Lewis, Boca Raton, 1995.

4. Jardim, W. F.; Quim. Nova 1998, 21, 671. E referências citadas. 